\title{
Effect of implementing structured communication messages on the clinical outcomes of unconscious patients
}

\author{
Sahar Younes Othman ${ }^{* 1}$, Mona Mohamed EL-hady ${ }^{2}$ \\ ${ }^{1}$ Critical Care and Emergency Nursing, Damanhour University, Behira, Egypt \\ ${ }^{2}$ Critical Care and Emergency Nursing, Mansoura University, Dakahlia, Egypt
}

Received: April 19, 2015

DOI: $10.5430 /$ jnep.v5n9p117

\author{
Accepted: June 17, 2015 \\ Online Published: July 5, 2015 \\ URL: http://dx.doi.org/10.5430/jnep.v5n9p117
}

\begin{abstract}
Background: Patient communication is one of the most important factors associated with quality of care and patient safety, especially in Intensive Care Units (ICUs). However, relatively little is known about the different aspects of communication with unconscious patients, and the effect of communication and outcome measures. Aim: This study aimed to examine effects of implementing structured communication messages (SCMs) on the clinical outcomes of unconscious patients.

Methods: A quasi-experimental design was utilized. Sixty unconscious patients were selected from three ICUs of Emergency Hospital of Mansoura University and two ICUs at Main Hospital of Mansoura University. Patients were randomly allocated into two groups (intervention and control group) 30 patients in each. Four tools were used for data collection: physiological adverse events (PAE) assessment tool including (hyperthermia, hypothermia, tachycardia, bradycardia, hypertension, hypotension, hypovolemia, hypervolemia, desaturation, bradypnea, ventilatory distress, hyperglycemia or hypoglycemia), Full Outline of Un-Responsiveness (FOUR) scale, Behavioural Pain Scale (BPS), and Motor Activity Assessment Scale (MAAS).

Results: The implementation of SCMs was associated with a decreased incidence of PAE and a statistically significant positive effect on level of consciousness revealed by FOUR scale. Patients in the intervention group maintained in MAAS level (2-3) (calm, cooperative and responsive to touch). The BPS in intervention group significantly decreased following the application of SCMs than control group. Moreover, the mean duration of mechanical ventilation and length of stay in ICU were significantly shorter in the intervention group than in the control group.

Conclusions: The SCMs developed, has been shown to facilitate the communication with the unconscious patients therefore, it is recommended for use in a nurse's daily routine of unconscious patients.
\end{abstract}

Key Words: Consciousness level, Coma, Verbal communication, Non-verbal communication, Structured communication

\section{INTRODUCTION}

Effective communication is one of the foundations of professional nursing practice and the art of caring holistically for patients. Indeed, as nurses are the professional group that has the greatest contact with patients, ensuring their communication needs are fully met has been established as one of the most important skills of nursing. Nurses use communication strategies to give directions, offer reassurance, provide consolation, commiserate, interpret, receive information, and carry out different duties. Without communication nurses, can neither assess, plan, implement, or evaluate care effectively. ${ }^{[1-4]}$

\footnotetext{
${ }^{*}$ Correspondence: Sahar Younes Othman; Email: younes_19@yahoo.com; Address: Critical Care and Emergency Nursing, Damanhour University, Damanhour, Egypt. 
Intensive care units (ICUs) differ from other hospital settings because of the complexity of patient health problems, the treatment modalities used and the environment. The ICU environment is often noisy, technical and fear inducing to many patients. ${ }^{[5]}$ Patients admitted to ICUs are usually facing life-threatening illnesses. Their critical condition requires technological support, modern facilities, and invasive and noninvasive procedures for the purpose of measuring, monitoring and regulating physiological functions. In a rush to be stabilized physiologically, procedures are carried out by critical care nurses $(\mathrm{CCNs})$ in a mechanical fashion with poor communication. Often nurses concentrate much to do their technical work rather than talking to the patients. This status would inevitably affect patients' ability to communicate, represent their thoughts, feelings, desires and needs clearly to others. ${ }^{[6]}$ Communication with critically ill patients in ICUs generates specific challenges for $\mathrm{CCNs}$, and demands well-developed skills. Numerous barriers to communication exist such as: impaired consciousness; sedation, and presence of artificial airways. ${ }^{[7]}$ While caring for such patients communication can be easily missed or nurses consider communication is unimportant. ${ }^{[3]}$ Inadequate nurse-patient communication results in increased levels of stress and anxiety. Thus, communication within the ICU environment is of paramount importance, and effective communication is an essential aspect of nurses' care. ${ }^{[6]}$

Most patients in ICUs are unconscious, sensory deprived and have limited mobility due to disease process and/or medications. ${ }^{[6]}$ The unconscious patients are disoriented to place, time and person, have no control over themselves or their environment and are highly dependent on the nurse. ${ }^{[8]}$ Though they are not able to respond to external stimuli, it is documented that many patients have regained consciousness and given accurate accounts of what happened to them in their unconscious stage. ${ }^{[3,9,10]}$ According to Sisson, ${ }^{\left[{ }^{[9]}\right.}$ hearing is the last sense to go when a person becomes unconscious. Early research conducted by Walker et al. ${ }^{[11]}$ reported that the majority of unconscious patients has normal brainstem auditory evoked responses and indicated that they may hear. Lawrence ${ }^{[12]}$ investigated 100 former patients' views of communication in ICUs during the period of unconsciousness. Most participants revealed that they heard, understood, and emotionally responded to what was said to them. Moreover, LaPuma et al. ${ }^{[13]}$ suggested that talking to comatose patients may have considerable therapeutic value. Recently, Goudarzi et al. ${ }^{[14]}$ reported that auditory stimulation by familiar voice may have an effect on promotion of level of consciousness (LOC) in unconscious patients. Not only do these studies all affirm the importance of communicating with unconscious or sedated patient, but they also address the importance of the content of such communication. ${ }^{[6]}$

Although verbal communication is mostly viewed as an interactive process, its importance to unconscious patients can be perceived as they have a considerable need for information and support. ${ }^{[15]}$ Information received by unconscious patients may assist in reducing stress. This connection can be demonstrated using Lazarus and Folkman's ${ }^{[16]}$ theory of stress and coping process. The unconscious patients are under stress because they are likely to misunderstand and be unsure of what is happening. Verbal communication to unconscious patients can reduce stress by facilitating the patients' use of adaptive coping mechanisms. ${ }^{[15]}$

The importance of communication to unconscious patients has long been known. Both qualitative and quantitative studies have shown evidence of the benefits of effective communication. ${ }^{[3,10,17]}$ The unconscious patients have a considerable need for information and support, so verbal communication can provide orientating and meaningful sensory input to these patients. Information received by the unconscious patients may assist in reducing stress, helping patients preserve selfidentity and self-esteem and reduce social isolation. ${ }^{[1,10]}$ In addition, communication experts emphasized that the use of nonverbal communication in the form of caring touch with verbal communication has a considerable outcome for unconscious patients. It can enhance the messages patients receive, help to meet patients' psychological needs and prevents psychosis withdrawal and delirium, which may contribute to psychological stress, disorientation, anxiety and isolation. ${ }^{[18]}$ Despite its importance, there is evidence that communication in ICUs is not sufficiently implemented in practice. ${ }^{[1,6,15,19-21]}$ Researchers have also seen that nurses talk very little to the unconscious patient while doing any procedure. Even if they communicate it is to check only the patient's reflexes. ${ }^{[6,19,20]}$

\subsection{Significance of the study}

Patient communication has long been recognized as a research priority in critical care, unfortunately, many of the studies in the area of communication with unconscious patients suffer from design weaknesses, such as nonstandardized practices, so definitive recommendations for clinical practice are difficult to make. ${ }^{[6,10]}$ However, there is no evidence that communication with unconscious patients causes any harm or serious physiological adverse events (PAE). In addition, recent developments in the field of functional neuroimaging have resulted in dramatic evidence that unconscious patients can hear and seemingly retain some cognitive ability. ${ }^{[22]}$ Although studies have been conducted to explore the clinical benefits of communicating with unconscious patients, none of them was conducted in Egypt. We 
still do not have a precise answer about the clinical outcomes to nurse-communication with unconscious patients. Thus there is the need for continued research in this area to develop a structured communication messages (SCMs) that may be used by $\mathrm{CCNs}$ when communicating with unconscious patients.

\subsection{Aim of the study}

The aim of the study is to evaluate the effect of implementing SCMs on the clinical outcomes of unconscious patients.

\subsection{Research hypothesis}

- H1. Unconscious patients who are subjected to SCMs (intervention group) will exhibit improved consciousness than (control group) those who do not.

- H2. Unconscious patients who are subjected to SCMs (intervention group) will experience less pain than (control group) those who do not.

- H3. Unconscious patients who are subjected to SCMs (intervention group) will exhibit a less deep sedation level than (control group) those who do not.

- H4. Unconscious patients who are subjected to SCMs (intervention group) will have a significant lower incidence of PAE than (control group) those who do not.

- H5. Unconscious patients who are subjected to SCMs (intervention group) will have a shorter duration of mechanical ventilation and length of ICU stay than (control group).

\section{MeTHODS}

\subsection{Research design}

A Quasi Experimental design was used in carrying out the current study.

\subsection{Setting}

This study was conducted in in three ICUs at Emergency Hospital of Mansoura University (trauma 1, 2, 3) and two ICUs at Main Hospital of Mansoura University (Neurological ICU and Chest ICU). These units consist of thirty beds separated by curtains; it admits approximately 120 patients a month $70 \%-80 \%$ of patients have altered consciousness and connected to mechanical ventilation (MV).

\subsection{Subjects}

A convenience sampling method was used during the current study. Sixty adult patients of both sexes admitted to the previously mentioned ICUs were recruited for this study using the following inclusion and exclusion criteria: Inclusion Criteria: patient's aged $\geq 18$ years old, total FOUR

Published by Sciedu Press score between 6 and 9, expected mechanically ventilated $\geq 48$ hours, sedation level between 1-4 on the MAAS, and haemodynamically stable. Exclusion Criteria: patients were excluded from the study if they had one of the following criteria: history of impaired hearing; excessive consumption of alcohol and/or narcotic substances; diagnosed injury of the auditory pathways and the cerebral cortex, receiving resuscitative therapies, induced coma by infusion of neuromuscular blockade, quadriplegia and skull fractures in the temporal area. Patients were assigned randomly into two groups (control and intervention group) 30 patients in each. The control group received routine communication practices for dealing with unconscious patients provided by $\mathrm{CCNs}$, whereas the intervention group received SCMs provided by the researchers.

\subsection{Tools}

Four tools were used for data collection in this study.

\section{Tool I: Physiological adverse events assessment tool}

This tool was developed by the researchers to monitor the patients for the occurrence of physiological adverse events (PAE) after communication throughout the study period. This tool is composed of two parts:

Part One: "Patient's socio-demographic and baseline characteristics" which include patient's age, sex, marital status, diagnosis, level of education, level of consciousness (LOC) in the beginning of the study, ICU length of stay (ICU LOS) and duration of mechanical ventilation (MV).

Part two: Parameters of PAE including "temperature (T), systolic blood pressure (SBP), diastolic blood pressure (DBP), heart rate $(\mathrm{HR})$, oxygen saturation $\left(\mathrm{SpO}_{2}\right)$, respiratory rate (RR), central venous pressure (CVP), and blood glucose level (BGL)". The PAE parameters were organized in a flow sheet to document patient's data from the beginning to the end of the study. These parameters were defined as appearance of clinically relevant changes after communication including the followings:

- Tachycardia: heart rate $\geq 100$ beats/minute (b/min)

- Bradycardia: heart rate $\leq 60 \mathrm{~b} / \mathrm{min}$

- Hypertension: SBP $\geq 140 \mathrm{mmHg}, \mathrm{DBP} \geq 90 \mathrm{mmHg}$

- Hypotension: $\mathrm{SBP} \leq 95 \mathrm{mmHg}, \mathrm{DBP} \leq 60 \mathrm{mmHg}$

- Hypovolemia: $\mathrm{CVP}<3 \mathrm{cmH}_{2} \mathrm{O}$

- Hypervolemia: CVP $>8 \mathrm{cmH}_{2} \mathrm{O}$

- Hyperthermia: $\mathrm{T} \geq 37.5^{\circ} \mathrm{C}$

- Desaturation: oxygen saturation $\leq 90 \%$

- Bradypnea: respiratory rate $\leq 12$ cycle/min

- Ventilatory distress: severe ventilator asynchrony (nonstop coughing or impossible ventilation) and/or tachypnea (respiratory rate $\geq 35$ cycle/min) 
- Hyperglycemia: blood glucose level (BGL) $\geq 200$ $\mathrm{mg} / \mathrm{dl}$

- Hypoglycemia: BGL $<70$ mg/dl

Tool II: Full Outline of Un-Responsiveness (FOUR) scale This scale was adopted from Wijdicks ${ }^{[23]}$ to assess patient's level of consciousness after conducting communication practices. It has 4 components: eye responses, motor responses, brainstem reflexes, and respiration pattern (including mechanical ventilation). The maximum score for the four items is 4 . The total score ranges from 0 to 16 . A score of 0 on the FOUR scale assumes the absence of brainstem reflexes and breathing while, 16 indicates full consciousness.

\section{Tool III: Behavioural Pain Scale (BPS)}

This scale was adopted from Payen et al. ${ }^{[24]}$ to assess patient's comfort/pain level after performing communication practices. It is based on the sum score of three behavioural expressions: facial expressions (relaxed, partially tight, fully tightened, or grimacing), upper limb movements (no movement, partially bent, fully bent with finger flexion, or permanently retracted) and compliance with mechanical ventilation (tolerating movement, coughing with movement, fighting ventilator, or unable to control ventilation). Each item of the three behavioural expressions is scored from 1 to 4 , with higher numbers indicating higher levels of discomfort. The total BPS score can range from 3 (no pain) to 12 (most pain).

\section{Tool IV: Motor Activity Assessment Scale (MAAS)}

This scale is adopted from Devlin et al. ${ }^{[25]}$ to assess patients' levels of sedation or irritability and restlessness after performing communication practices. It is a 7-point scale ranging from 0 (unresponsive) to 6 (dangerously agitated). The levels $0-2$ indicate a deeper sedation level affecting the patients' motor activity, wakefulness and consciousness. When patients are calm and cooperative, it indicates level 3 , restless and cooperative indicates level 4 and increased motor activity, agitation and uncooperative indicates level 5-6.

\subsection{Validity and reliability of tools}

All instruments were reviewed by 5 experts in the field of critical care nursing to test its content validity and ascertain that the tools were relevant, understood, and applicable. The reliability and validity of FOUR were acceptable in another research done by Iyer et al. ${ }^{[26]}$ (Cronbach $\alpha 0.87$ and a Kappa coefficient of 0.99). The reliability of the BPS was assessed by Payen et al. ${ }^{[24]}$ and a Kappa coefficient of 0.94 was reported. Concerning MAAS, it was previously tested for validity and reliability and was considered as a valid and reliable sedation scale for use by nurses for mechanically ventilated patients. ${ }^{[25]}$

\subsection{Pilot study}

A pilot study was performed after the development of the tools and before starting data collection on $10 \%$ of the study sample (6 patients) who were excluded from the total sample. The aim of the pilot study was to determine the clarity, feasibility, applicability and determine the required time to fulfill the designed tools. Then accordingly necessary modifications were done.

\subsection{Fieldwork}

\subsubsection{Administrative and ethical considerations}

Approval was obtained from the Ethics Committee of the Faculty of Nursing at the Mansoura University. Moreover, permission to conduct the study was taken from the hospital responsible authorities after explanation of the aim of the study. There were no risks that can affect the studied patients during the implementation of this study. All patients were assigned a code number to ensure confidentiality. The researcher consulted the patient's closest relative for information about his/her opinion on patients' participation in the study and consent was obtained from them. Patients' relatives were also assured that if they did not wish to participate in the study, this would have no effect on the quality of care provided. The care of both patients in the control and intervention groups was, however, unchanged before and after the period of communication. The ethical demand of doing well, not harming and being fair, thereby appeared to have been met.

\subsubsection{Procedure of data collection}

The actual fieldwork started at the beginning of August 2014 and was completed by the end of January 2015. It was conducted on four phases; observation phase, preparation of SCMs phase, implementation phase and evaluation phase.

\section{Phase one: Observation phase}

During this phase, the researchers observed clinical outcomes for patients in the control group who received the routine communication practices provided by CCNs in the intended ICUs. Patients in this group were followed up by the researchers after 24 hours of ICU admission until ICU discharge. Data were collected by assessing clinical outcomes after nursing communication practices that were performed during the routine daily care (complete bed bath, tracheal tube suction, physiotherapy, patient repositioning and wound dressing changing) which were performed in the morning (8-9 Am) and at the end of evening shift (7-8 Pm).

- The researchers documented patient's sociodemographic data and baseline characteristics at patient's admission using part one of tool I.

- Patients' parameters of PAE including (T, HR, SBP, 
DBP, CVP, $\mathrm{SpO}_{2}, \mathrm{RR}$, and BGL) were assessed and recorded (tool I part two) twice daily (8-9 Am and 7-8 Pm) until ICU discharge. The appearance of any PAE (hyperthermia, hypothermia, tachycardia, bradycardia, hypertension, hypotension, hypovolemia, hypervolemia, desaturation, bradypnea, ventilatory distress, hyperglycemia or hypoglycemia) was recorded on the same tool. The incidence of PAE is defined by the proportion of patients who developed at least one PAE while being communicated.

- Patient's LOC was assessed by FOUR scale twice daily (8-9 Am and 7-8 Pm) until ICU discharge using Tool II.

- Patient's pain/comfort level was assessed by BPS twice daily (8-9 Am and 7-8 Pm) until ICU discharge using Tool III.

- Patient's sedation or restlessness level was assessed by MAAS twice daily (8-9 Am and 7-8 Pm) until ICU discharge using Tool IV.

- Finally duration of MV and ICU LOS were documented (part one of tool I). The duration of MV in days was defined as the initial time when the mechanical ventilator was applied until the ventilator is discontinued. The ICU LOS in days was calculated by determining the date and time of ICU admission and the date and time of transfer out of the ICU or death, and summing the total number of days.

\section{Phase Two: Preparation of SCMs}

This phase was accomplished by the following steps:

\section{1) Formulation of verbal messages}

- An extensive literature review was conducted by the researchers to identify all available evidences concerning verbal communication with unconscious patients. The content of verbal messages was based on the results reported in the literature, ${ }^{[1,10,27]}$ and the cooperation of a group of experts (critical care nursing, speech and language therapists). The results of the content analysis were used to construct the structured verbal messages that were utilized during conversation with unconscious patients. The expert group proposed the construction of a message which should include both pleasant contents (e.g., Your family told me they really like you and that they wish you recover quickly) and orders (e.g., Mr./Mrs. A, I'm here to help you, come on, open your eyes).

- The structured verbal messages consisted of three parts: presentation and orientation; information; functional assessment and stimulation see (see Figure 1). The first part included contents with the purpose of in- troducing the speaker and orientating the conversation in space and time. This part was composed of calling the patient by his name, greeting the patient, identifying the health professional or relative (name, profession or relationship), stating the date, day of the week and the weather, and explaining their current location. Finally, explaining the procedure before performing it and reassuring the patient at the end of each procedure; explaining patient's progress, and communicating the present condition of the patient. The second part consisted of providing the patient with information about: current affairs; saying something about their family life and some sentences about recovery and coming back to family in the future; sweet memories, and telling a message of affection and with an optimistic perspective. The third part of the verbal message had the purpose of assessing the functional abilities and response to stimulation of the patients. This part was composed of instructions (e.g., open your eyes) and an evaluation of their responses, including verbal replies, opening of eyes and motor responses.

- The standardized criteria for verbal communication to unconscious patients was identified such as: using the appropriate voice tone, not speaking too loud or shouting, avoiding parallel talk while care procedures are performed, communicating with the patient directly, simplifying language by using short and uncomplicated sentences, repeating the content words or key words to clarify meaning as needed, maintaining a natural conversational manner appropriate for an adult, minimizing distractions, and encouraging any type of communication feedback from patient.

\section{2) Formulation of non-verbal messages}

The content of structured non-verbal communication was based on the results reported in the literature. ${ }^{[21,27]}$ It included therapeutic touch, facial expressions, posturing and eye contact. The three types of therapeutic touch were included: caring touch (gives comfort and reassurance to the patient); task touch which is concerned with performing nursing procedures; and protective touch which is concerned with protecting the patient from accidents.

\section{Phase Three: Implementation phase}

- During this phase the patient's closest relative of the intervention group was interviewed to determine the patient's social history and personality characteristics. After 24 hours of patient's admission to the intended ICUs, the researcher reviewed patient's chart to document socio-demographic and health relevant data using part one of tool I. 
- Before each communication with the patient, the researcher prepared the room; curtains were drawn to provide privacy, and researcher tried to keep the surroundings as quiet as possible and ensured that the patient is in a resting position (semi-fowler's position or appropriate position to the applied procedure). Then the researcher stood beside the patient's bed (facing the patient to be in the visual field).

- Verbal communication practices were performed each time the researcher contacted patient according to the developed SCMs. The time allocated as follows: 5 minutes for presentation and orientation; 5 minutes for information and 5 minutes was for functional assessment and stimulation.

- Nonverbal communication practices were performed in combination with verbal practices. The researcher leaned forward and smiled each time she spoke to the patient, maintained eye contact throughout the procedure, taped on patient shoulder and hand before and after procedure.

- If the researcher perceived signs of discomfort during communication practice, the intervention was interrupted.

- The family members were encouraged to communicate "verbally and non-verbally" with their patients during visiting hours. Family verbal communication covered spiritual support, reaffirming that the patient is not alone; concerns about the patient's recovery; the wish for the patients to return to family life; and should not worry about external events; family is concerned with reporting the visits, memories about daily life and news from home. While, nonverbal communication methods used by family members consisted of taping on patient's face and arms, maintaining eye contact, smiling, and leaning forward during talking to the patient.

- Patients in the intervention group were followed up by the researcher after 24 hours of ICU admission until discharge. Patients' PAE parameters including (T, HR, SBP, DBP, CVP, $\mathrm{SpO}_{2}, \mathrm{RR}$, and BGL) were assessed and recorded (tool I part two) twice daily (8-9 Am and 7-8 Pm) until ICU discharge. The appearance of any of PAE (hyperthermia, hypothermia, tachycardia, bradycardia, hypertension, hypotension, hypovolemia, hypervolemia, desaturation, bradypnea, ventilatory distress, hyperglycemia or hypoglycemia) was recorded on the same tool. The incidence of PAE is defined by the proportion of patients who developed at least one PAE while being communicated.

- Patient's LOC was also evaluated by the FOUR scale twice daily until discharge using Tool II. Then patient's pain/comfort level was assessed by BPS twice/day until discharge using Tool III. Patient's sedation or restlessness level was assessed by MAAS twice daily until discharge using Tool IV. Finally ICU LOS and duration of MV (in days) were documented in part one of tool I.

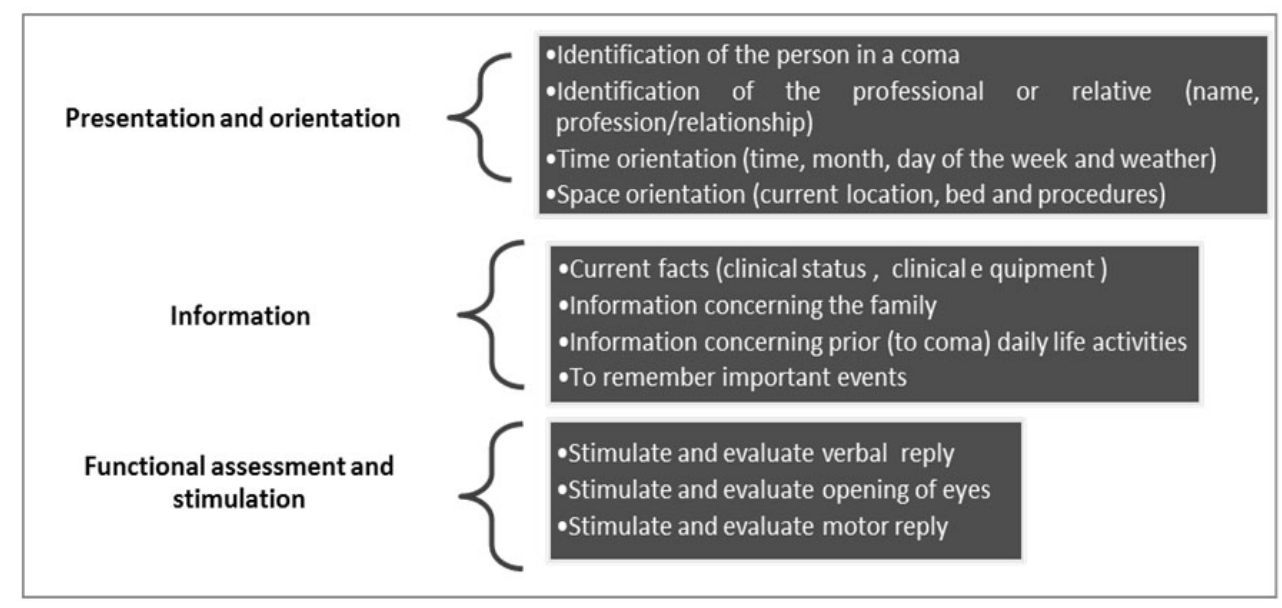

Figure 1. Composition of structured verbal messages

\section{Phase Four: "Evaluation Phase"}

During this phase the clinical outcomes of both groups (control and intervention) were evaluated. The PAE (hyperthermia, hypothermia, tachycardia, bradycardia, hyper- tension, hypotension, hypovolemia, hypervolemia, desaturation, bradypnea, ventilatory distress, hyperglycemia or hypoglycemia), FOUR score, BPS score, and MAAS score were considered as primary outcomes. While overall duration of MV and ICU LOS, were considered as secondary outcomes. 


\subsection{Statistical analysis}

The collected data were organized, tabulated and statistically analyzed using the Statistical Package for Social Studies (SPSS) version 21. Following data entry, checking and verification processes were carried out to avoid any errors during data entry. The normality of data was first tested with Shapiro-Wilk test. Qualitative data were described using number and percent. Association between categorical variables was tested using Chi-square test. When $25 \%$ of the cells have expected count less than 5, Fisher exact test was used. Continuous variables were presented as mean \pm SD (standard deviation). The two groups were compared with Student t test (parametric data) and Mann-whitney test (non parametric data). For all above mentioned statistical tests done, the threshold of significance is fixed at $5 \%$ level ( $p$-value). $P$-Values, which were less than .05 , were considered as statistically significant, and, less than $<.001$, were considered as very highly statistically significant.

\section{RESULTS}

As shown in Table 1, a total of 60 patients were enrolled in this study. Comparing the two groups (control and intervention) in relation to socio-demographic data and baseline characteristics, these groups were comparable and no significant differences were noted; in other words, they can be considered homogeneous.

Table 1. Socio-demographic data and baseline characteristics of the study population $(\mathrm{N}=60)$

\begin{tabular}{|c|c|c|c|c|c|c|}
\hline \multirow{2}{*}{ Variable } & \multicolumn{2}{|c|}{ Control } & \multicolumn{2}{|c|}{ Intervention } & \multicolumn{2}{|c|}{ Test of significance } \\
\hline & n & $(\%)$ & $\mathbf{n}$ & $(\%)$ & $t / \chi^{2}$ & $\boldsymbol{P}$ \\
\hline Age (years) $($ mean \pm SD $)$ & \multicolumn{2}{|c|}{$37.53 \pm 11.11$} & \multicolumn{2}{|c|}{$37.70 \pm 11.02$} & $t=0.058$ & .954 \\
\hline \multicolumn{7}{|l|}{ Gender } \\
\hline Female & 18 & 60 & 16 & 53.3 & 0.271 & .602 \\
\hline Male & 12 & 40 & 14 & 46.7 & & \\
\hline \multicolumn{7}{|l|}{ Level of Education } \\
\hline Illiterate & 9 & 30 & 13 & 43.3 & 1.148 & .284 \\
\hline Literate & 21 & 70 & 17 & 56.7 & & \\
\hline \multicolumn{7}{|l|}{ Diagnosis } \\
\hline Trauma & 18 & 60 & 19 & 63.3 & & \\
\hline Respiratory disorders & 10 & 33.3 & 9 & 30 & 0.264 & .611 \\
\hline Neurological disorders & 2 & 6.7 & 2 & 6.7 & & \\
\hline FOUR score on admission (mean $\pm \mathrm{SD}$ ) & \multicolumn{2}{|c|}{$7.51 \pm 2.06$} & \multicolumn{2}{|c|}{$7.38 \pm 1.71$} & $t=0.859$ & .391 \\
\hline
\end{tabular}

Note. T: T-test; $\chi^{2}$ : Chi-Square Test; FOUR: Full Outline of Un-Responsiveness scale.

\subsection{Effect of SCMs on the LOC}

As presented in Table 2, the average mean of LOC revealed by FOUR scale for control and intervention groups at the beginning of study were $7.51 \pm 2.06 v s .7 .38 \pm 1.71$ respectively with no significance difference between the two groups $(P>.05)$. Mean FOUR scores after commencing the SCMs for intervention group were significantly higher than that of control group ( $11.83 \pm 2.09 v s .8 .56 \pm 1.72$ respectively, $p$ $\leq .001)$. As shown in Figure 2 despite that the two groups were similar at baseline, patients in the intervention group had a higher FOUR scores all over the study period than patients in the control group.

Table 2. Mean differences of the Full Outline of Un-Responsiveness Score at the beginning and end of the study in the intervention and control groups

\begin{tabular}{|c|c|c|c|c|c|}
\hline \multirow{2}{*}{ Variable } & \multirow{2}{*}{ Time } & \multirow{2}{*}{$\begin{array}{l}\text { Control } \\
\text { Mean } \pm \text { SD }\end{array}$} & \multirow{2}{*}{$\begin{array}{l}\text { Intervention } \\
\text { Mean } \pm \text { SD }\end{array}$} & \multicolumn{2}{|c|}{ Test of significance } \\
\hline & & & & $t$ & $p$ \\
\hline \multirow{2}{*}{ FOUR } & Beginning & $7.51 \pm 2.06$ & $7.38 \pm 1.71$ & .859 & .391 \\
\hline & End & $8.56 \pm 1.72$ & $11.83 \pm 2.09$ & 3.567 & $\leq .001 *$ \\
\hline
\end{tabular}

Note. FOUR: Full Outline of Un-Responsiveness scale; $T$ : T-test; *: Significant at $P \leqslant .05$.

\subsection{Effect of SCMs on pain level}

As illustrated in Table 3, the mean scores of pain at the beginning of the study according Behavioural Pain Scale (BPS) in control and intervention groups were relatively converPublished by Sciedu Press gent $(6.19 \pm 1.93$ vs. $6.85 \pm 1.87$ respectively); with no significance difference between the two groups $(P=.183)$. Documented BPS at the end of the study showed that patients' pain in intervention group was significantly dropped 
following the application of SCMs than control group $3.43 \pm$ levels of pain all over the study period with application of 1.80 vs. $10.08 \pm 2.01$ respectively $(P \leq .000)$. As presented $\mathrm{SCMs}$ compared with the pain levels in control group.

in Figure 3, patients in the intervention group showed lower

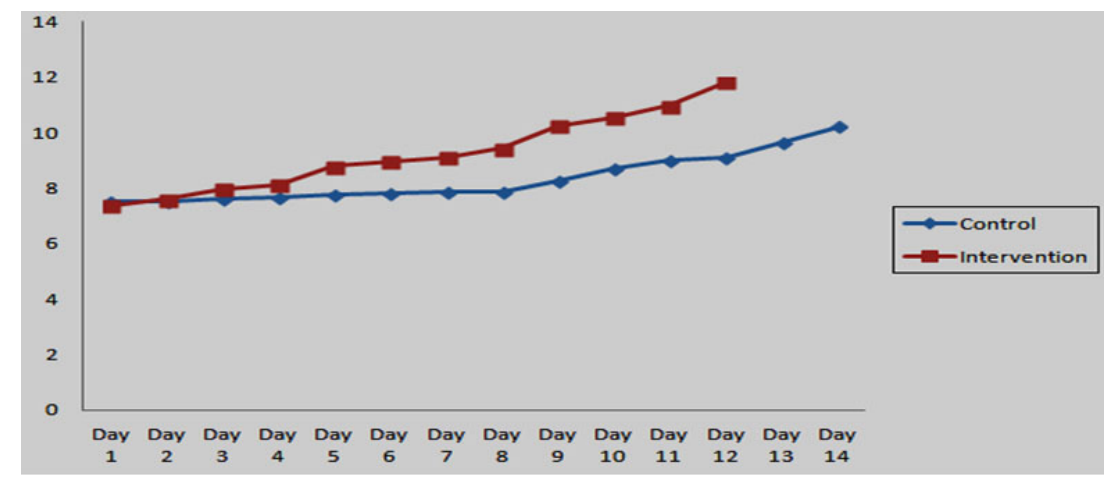

Figure 2. The change of the Full Outline of Un-Responsiveness Score over the study period in the intervention and control groups

Table 4 summarizes a comparison between intervention and control groups regarding BPS sub-items throughout the study period. The study findings revealed that; there were no significant differences of BPS sub-items (facial expression, upper limbs and compliance with ventilation) between the two groups at the beginning of the study $(p=.484, .067, .657$ respectively). However, after commencing the SCMs for intervention group the BPS sub-items (facial expression, upper limbs and compliance with ventilation) were significantly lower than the control group $(1.01 \pm .741$ vs. $3.13 \pm .859$; $1.19 \pm .611$ vs. $3.88 \pm .895 ; 1.09 \pm .531$ vs. $2.97 \pm .907$ respectively, $p \leq .001)$. The study results indicated that intervention group had relaxed facial expression, relaxed upper limbs and tolerating movement of mechanical ventilation throughout the study period. On the opposite side, control group had fully tightened facial expression, fully bent upper limbs and fighting mechanical ventilator most of time of the study period.

Table 3. Mean differences of the Behavioral Pain Scale scores at the beginning and end of the study in the intervention and control groups

\begin{tabular}{|c|c|c|c|c|c|}
\hline \multirow{2}{*}{ Variable } & \multirow{2}{*}{ Time } & \multirow{2}{*}{$\begin{array}{l}\text { Control } \\
\text { Mean } \pm \text { SD }\end{array}$} & \multirow{2}{*}{$\begin{array}{l}\text { Intervention } \\
\text { Mean } \pm \text { SD }\end{array}$} & \multicolumn{2}{|c|}{ Test of significance } \\
\hline & & & & $t / Z$ & $p$ \\
\hline \multirow{2}{*}{ BPS } & Beginning & $6.19 \pm 1.93$ & $6.85 \pm 1.87$ & $t=1.35$ & .183 \\
\hline & End & $10.08 \pm 2.01$ & $3.43 \pm 1.80$ & $Z=13.50$ & $\leq .000^{*}$ \\
\hline
\end{tabular}

Note. BPS: Behavioral pain scale; $T$ : $T$-test; Z: Mann-Whitney test; : Significant at $P \leqslant .05$.

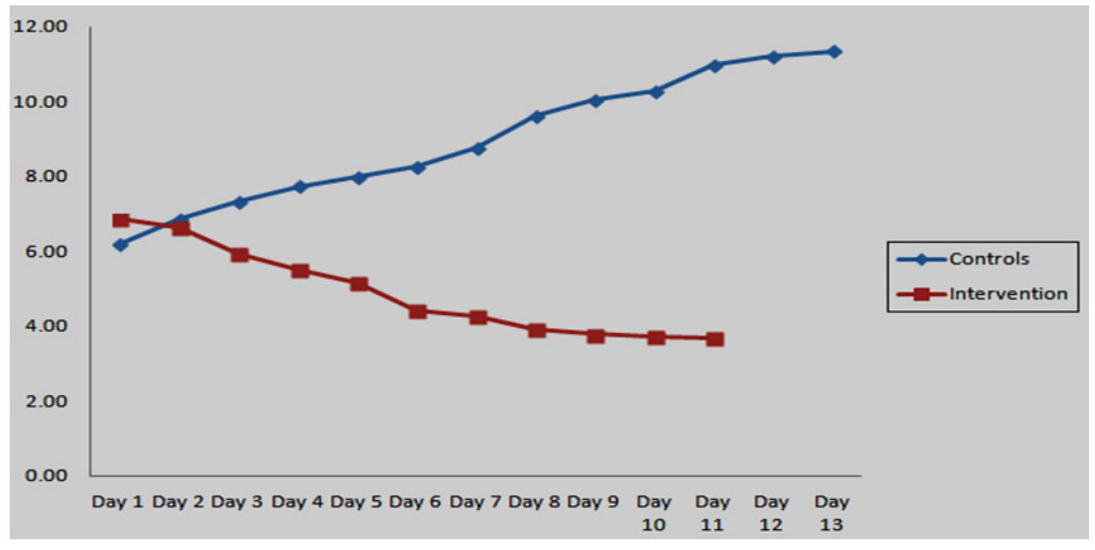

Figure 3. Change in the behavioral pain scale score over the study period in the intervention and control groups 
Table 4. Comparison between control and intervention groups regarding Behavioural Pain Scale sub-items throughout the study period

\begin{tabular}{llllll}
\hline \multirow{2}{*}{ Sub-items of BPS } & \multirow{2}{*}{ Time } & Control & \multicolumn{2}{c}{ Intervention } & \multicolumn{2}{c}{ Test of significance } \\
\cline { 3 - 6 } & & Mean \pm SD & Mean \pm SD & tZ & $\boldsymbol{p}$ \\
\hline \multirow{2}{*}{ Facial expression } & Beginning & $2.41 \pm .884$ & $2.57 \pm .781$ & $t=0.70$ & .484 \\
& End & $3.13 \pm .859$ & $1.01 \pm .741$ & $Z=10.24$ & $\leq .001^{*}$ \\
\multirow{2}{*}{ Upper limbs } & Beginning & $2.44 \pm .898$ & $2.84 \pm .655$ & $t=1.87$ & .067 \\
& End & $3.88 \pm .895$ & $1.19 \pm .611$ & $Z=13.60$ & $\leq .001^{*}$ \\
Compliance with ventilation & Beginning & $1.31 \pm .970$ & $1.22 \pm .531$ & $Z=-0.45$ & .657 \\
& End & $2.97 \pm .907$ & $1.09 \pm .531$ & $Z=9.80$ & $\leq .001^{*}$ \\
\multirow{2}{*}{ Total (BPS) } & Beginning & $6.19 \pm 1.93$ & $6.85 \pm 1.872$ & $t=1.28$ & .207 \\
& End & $10.08 \pm 2.01$ & $3.43 \pm 1.80$ & $Z=13.50$ & $\leq .000^{*}$ \\
\hline
\end{tabular}

Note. BPS: Behavioral pain scale; $T$ : $T$-test; Z: Mann-Whitney test; *: Significant at $P \leqslant .05$.

\subsection{Effect of SCMs on sedation level}

As shown in Table 5, the Motor Activity Assessment Scale (MAAS) at the beginning of the study was similar in the control and intervention groups $(1.54 \pm 0.96 v s .1 .18 \pm 1.33$ respectively $P>.05)$. When the mean scores of this scale were compared between the two groups at the end of the study, it is clear that patients' sedation in intervention group was significantly in more appropriate level than control group $(P=.032296)$. Figure 4 demonstrates change in the MAAS over the study period in the intervention and control groups. Compared with control group, patients in the intervention group seemed to be more alert and calm according to the MAAS throughout the study period. The results also show that patients in the intervention group who received SCMs tended to "stay" in MAAS level 2-3 (calm, cooperative and responsive to touch). It can be observed from the same figure that patients in the control group seemed to be more restlessness throughout the study period.

Table 5. Mean differences of the Motor Activity Assessment Scale at the beginning and end of the study in the intervention and control groups

\begin{tabular}{|c|c|c|c|c|c|}
\hline \multirow{2}{*}{ Behavioral Responses } & \multirow{2}{*}{ Time } & \multirow{2}{*}{$\begin{array}{l}\text { Control } \\
\text { Mean } \pm \text { SD }\end{array}$} & \multirow{2}{*}{$\begin{array}{l}\text { Intervention } \\
\text { Mean } \pm \text { SD }\end{array}$} & \multicolumn{2}{|c|}{ Mann-Whitney test } \\
\hline & & & & $Z$ & $p$ \\
\hline \multirow{2}{*}{ MASS } & Beginning & $1.54 \pm 0.96$ & $1.18 \pm 1.33$ & 1.20 & .234203 \\
\hline & End & $1.91 \pm 1.48$ & $2.61 \pm 0.93$ & 2.19 & $.032296 *$ \\
\hline
\end{tabular}

Note. MASS: Motor Activity Assessment Scale; $Z$ : Mann-Whitney test; *: Significant at $P \leqslant .01$ *Motor Activity Assessment Scale.



Figure 4. Changes in the motor activity assessment scale over the study period in the intervention and control groups 


\subsection{Effect of SCMs on the incidence of PAE}

As presented in Table 6, the control group had a significantly higher incidence rate of PAE than patients in the intervention group. In relation to cardiovascular adverse events, the findings of the present study reveal that there was a highly significant difference between the two groups $(p \leq .001)$ as regards occurrence of tachycardia $(80 \%$ for control vs. $10 \%$ for intervention group), hypertension $(73.33 \%$ for control vs. $10 \%$ for intervention group) and hypervolemia (66.66\% for control vs. $13.3 \%$ for intervention group). Table 7 also shows that the average mean values of heart rate (HR) in the beginning of the study for control and intervention groups were $80.73 \pm 8.84$ vs. $82.95 \pm 7.41$ respectively with no significance difference between the two groups. The mean values of HR for the intervention group remained relatively constant after implementation of SCMs and throughout the study period. On the other hand, mean values of HR for the control group were fluctuating throughout the study period. The difference between the two groups was highly significant $p \leq .001$. The mean systolic blood pressure (SBP) values for intervention group also remained relatively constant throughout the study period $(114.85 \pm 6.79 \mathrm{mmHg} v s$. $114.04 \pm 9.36 \mathrm{mmHg}$ at the beginning and end of the study respectively). While the mean SBP of the control group increased from $113.15 \pm 7.02$ at the beginning of the study to $144.80 \pm 10.78 \mathrm{mmHg}$ by the end of the study. Also diastolic blood pressure did not dramatically change from beginning to the end of the study for the intervention group. But it was significantly increased among patients in the control group. The mean differences of central venous pressure (CVP) val- ues demonstrated that there was no significant difference between the two groups from beginning to the end of the study ( $P=.837, .149$ respectively). It can be noted from the same table that CVP values for intervention group were maintained within the normal range throughout the study period while, increased above normal values at the end of the study for control group.

Concerning respiratory adverse events, Table 6 shows a significant increase of patients who have developed desaturation (11 vs. 0), bradypnea (4vs. 1) and ventilator distress (23 vs. 4) in the control group greater than intervention group. As shown in Table 7, the respiratory rate and oxygen saturation levels remained almost unchanged throughout the periods of SCMs implementation for the intervention group. Values of oxygen saturation among control group were declined at the end of the study. The results indicated that statistically significant differences exist between the two groups ( $p \leq$ $.001)$.

Regarding metabolic adverse events, Table 6 explores that hyperthermia and hyperglycemia occurrence rate was significantly elevated in the control group than the intervention group. As noted in Table 7 the mean averages of blood glucose level (BGL) within intervention group decreased from $126.07 \pm 9.82$ at the beginning of the study to $124.13 \pm 9.39$ at the end of study. While BGL mean values for the control group was $125.83 \pm 8.56$ at the beginning of the study which was increased to $182.77 \pm 17.42$ at the end of study. The body temperature mean values remained relatively stable among the whole study sample.

Table 6. Comparison between control and intervention groups regarding the incidence rate of physiological adverse events $(\mathrm{N}=60)$

\begin{tabular}{|c|c|c|c|c|c|c|}
\hline \multirow{2}{*}{ Physiological adverse events } & \multicolumn{2}{|c|}{ Control } & \multicolumn{2}{|c|}{ Intervention } & \multicolumn{2}{|c|}{ Test of significance } \\
\hline & $\bar{n}$ & $(\%)$ & $\bar{n}$ & $(\%)$ & FET $/ \chi^{2}$ & $p$ \\
\hline \multicolumn{7}{|l|}{ Cardiovascular adverse events } \\
\hline Tachycardia & 24 & 80.0 & 3 & 10.0 & 29.69 & $\leqslant .001^{*}$ \\
\hline Bradycardia & 1 & 3.33 & 0 & 0.00 & FET & 1 \\
\hline Hypertension & 22 & 73.33 & 3 & 10.0 & 24.75 & $\leqslant .001 *$ \\
\hline Hypotension & 0 & 0.00 & 2 & 6.66 & FET & .492 \\
\hline Hypervolemia & 20 & 66.66 & 4 & 13.33 & 17.77 & $\leqslant .001 *$ \\
\hline Hypovolemia & 0 & 0.00 & 1 & 3.33 & FET & 1 \\
\hline \multicolumn{7}{|l|}{ Respiratory adverse events } \\
\hline Desaturation & 11 & 36.66 & 0 & 0.00 & 13.469 & $\leqslant .001^{*}$ \\
\hline Bradypnea & 4 & 13.33 & 1 & 3.33 & FET & .353 \\
\hline Ventilatory distress & 23 & 76.66 & 4 & 13.33 & 24.31 & $\leqslant .001 *$ \\
\hline \multicolumn{7}{|l|}{ Metabolic adverse events } \\
\hline Hyperthermia & 6 & 20.00 & 0 & 0.00 & FET & $.024^{*}$ \\
\hline Hyperglycemia & 9 & 30 & 2 & 6.66 & 5.455 & $0.02 *$ \\
\hline
\end{tabular}

Note. FET: Fisher exact test; $\chi^{2}$ : Chi-Square Test; *: Significant at $P \leqslant .05$. 
Table 7. Mean differences of physiological adverse events parameters between control and intervention groups throughout the study period

\begin{tabular}{|c|c|c|c|c|c|}
\hline \multirow{2}{*}{ PAEs parameters } & \multirow{2}{*}{ Time } & \multirow{2}{*}{$\begin{array}{l}\text { Control } \\
\text { Mean } \pm \text { SD }\end{array}$} & \multirow{2}{*}{$\begin{array}{l}\text { Intervention } \\
\text { Mean } \pm \text { SD }\end{array}$} & \multicolumn{2}{|c|}{ Independent student's $t$ test } \\
\hline & & & & $t$ & $p$ \\
\hline \multirow{2}{*}{ Heart rate } & Beginning & $80.73 \pm 8.84$ & $82.95 \pm 7.41$ & 1.05 & .296 \\
\hline & End & $120.05 \pm 8.72$ & $82.48 \pm 7.13$ & 18.27 & $\leq .001^{*}$ \\
\hline \multirow{2}{*}{ Systolic blood pressure } & Beginning & $113.15 \pm 7.02$ & $114.85 \pm 6.79$ & 0.95 & .344 \\
\hline & End & $144.80 \pm 10.78$ & $114.04 \pm 9.36$ & 11.80 & $\leq .001^{*}$ \\
\hline \multirow{2}{*}{ Diastolic blood pressure } & Beginning & $78.25 \pm 8.29$ & $78.17 \pm 5.87$ & 0.04 & .965 \\
\hline & End & $99.31 \pm 8.11$ & $78.07 \pm 5.69$ & 11.74 & $\leq .001^{*}$ \\
\hline \multirow{2}{*}{$\mathrm{CVP}^{* *}\left(\mathrm{CmH}_{2} \mathrm{O}\right)$} & Beginning & $9.56 \pm 2.11$ & $9.45 \pm 2.02$ & 0.21 & .837 \\
\hline & End & $10.06 \pm 6.76$ & $8.17 \pm 2.10$ & 1.46 & .149 \\
\hline \multirow{2}{*}{ Temperature $\left({ }^{\circ} \mathrm{C}\right)$} & Beginning & $36.52 \pm 0.501$ & $36.68 \pm 0.347$ & 1.44 & .155 \\
\hline & End & $37.09 \pm 1.49$ & $36.67 \pm 0.33$ & 1.51 & .137 \\
\hline \multirow{2}{*}{ Respiratory Rate (beat/minute) } & Beginning & $17.25 \pm 2.89$ & $17.85 \pm 2.24$ & 0.90 & .372 \\
\hline & End & $24.47 \pm 2.84$ & $17.70 \pm 2.21$ & 10.30 & $\leq .001^{*}$ \\
\hline \multirow{2}{*}{ Oxygen saturation (\%) } & Beginning & $97.46 \pm 3.02$ & $97.39 \pm 2.08$ & 0.10 & .917 \\
\hline & End & $93.99 \pm 3.06$ & $99.42 \pm 2.20$ & 7.89 & $\leq .001 *$ \\
\hline \multirow{2}{*}{ Blood glucose level } & Beginning & $125.83 \pm 8.56$ & $126.07 \pm 9.82$ & 0.10 & .919 \\
\hline & End & $182.77 \pm 17.42$ & $124.13 \pm 9.39$ & 16.23 & $\leq .001 *$ \\
\hline
\end{tabular}

Note. PAEs: Physiological Adverse Events; CVP: Central Venous Pressure; $T: T$-test ; *: Significant at $P \leqslant .05$.

\subsection{Effect of SCMs on secondary outcomes}

Table 8 displays comparison between control and intervention groups regarding secondary outcomes. The mean ICU LOS for the intervention group was $8.066 \pm 1.96$ day compared to $11.466 \pm 2.23$ day for the control group. The $t$-test reflects highly significant differences between the two groups $(P \leq .001)$. It was found that the mean duration of mechanical ventilation was significantly shorter in the intervention group than in the control group $(6.20 \pm 2.074$ days $v s .9 .80$ \pm 2.17 days respectively $P \leq .001)$.

Table 8. Comparison between control and intervention groups regarding secondary outcomes

\begin{tabular}{llllll}
\hline \multirow{2}{*}{ Secondary Outcomes } & Control & Intervention & & \multicolumn{2}{l}{ Independent student's $\boldsymbol{t}$ test } \\
\cline { 2 - 3 } \cline { 5 - 6 } & Mean \pm SD & Mean \pm SD & & $\boldsymbol{p}$ \\
\hline ICU LOS (day) & $11.466 \pm 2.23$ & $8.066 \pm 1.96$ & & 6.252 & $\leq .001^{*}$ \\
Duration of MV (day) & $9.80 \pm 2.17$ & $6.20 \pm 2.074$ & & 6.565 & $\leq .001 *$ \\
\hline
\end{tabular}

Note. ICU LOS: Intensive Care Unit Length of Stay; MV: Mechanical Ventilation; $T$ : $T$-test; *: Significant at $P \leqslant .05$.

\section{Discussion}

Caring for critically ill patients in ICUs is challenging for CCNs, particularly when patients are unconscious. Lack of quality and satisfying communication with those patients could have serious implications for their physical and psychological health. ${ }^{[28-30]}$ Unfortunately, the researchers, in their clinical experience have observed that majority of CCNs in the study settings did not communicate with unconscious patients effectively and there are no standards of care for communication with unconscious patients. National and international studies on nurse-patient interaction have been shown that nurses communicate minimally with unconscious

Published by Sciedu Press patients. ${ }^{[1,6,15,19,20,31]}$ In Egypt, Ibrahim ${ }^{[19]}$ and Gergis ${ }^{[31]}$ reported that CCNs spent very short time (less than $60 \mathrm{sec}$ ) in the verbal communication with unconscious patients and their communication included negative suggestions and social conversations with colleagues while ignoring the patient's presence. Similarly, a study was conducted on the experiences of critical care Jordanian nurses concerning communication with critically ill patients. It revealed that communication in critical care settings is not sufficiently implemented and unconscious patients received less communication and interaction than verbally responsive patients. ${ }^{[6]} \mathrm{In}$ response to this and based on a literature review of Jesus et 
$a l .{ }^{[1]}$ and Simões et al. ${ }^{[10]}$ the authors developed this study that includes a detailed, objective and systematic analysis of the effects of communication with unconscious patients using SCMs.

Indeed, in the present study as a baseline for comparison, the control group was comparable to the patients in the in tervention group; both groups had similar access to ICU services; their demographic profiles and baseline characteristics were similar. In contrast, after the implementation of SCMs for the intervention group, the findings showed clinically and statistically significant improvement of patients' condition. Regarding LOC revealed by FOUR scale, the study findings showed a significant increase in LOC among patients in the intervention group after implementation of SCMs compared to control group. This improvement can be explained through understanding coma arousal theories that emphasized on human brain grows and adapts through utilization and increasing environmental stimulation, this theory was the base in developing the current SCMs. ${ }^{[32]}$ There is sufficient evidence to support the assumption that increased mentation and emotional arousal may affect the unconscious patients. ${ }^{[33,34]}$ Also evidence from studies has illustrated that sensory deprivation leads to physical deterioration of the brain and sensory stimulation increases the level of arousal and awareness through stimulating the reticular activating system. ${ }^{[35]}$ Developments in neuroscience provide additional support for implementing sensory stimulation in unconscious patients to promote "rewiring" of neuronal networks. The brain has spare capacity and ability to reorganize its functions, whenever there is damage to one part of brain the spare or non-active areas assume the functions of damaged area by a process of reorganization. The brain also has capacity to duplicate neuronal pathway in case existing pathway is damaged. ${ }^{[32]}$ These explanations are in agreement with Urbenjaphol et al. ${ }^{[36]}$ and Karma and Rawat ${ }^{[37]}$ who reported that application of appropriate arousal practices improves recovery of consciousness.

The current study findings are consistent with results of Goudarzi et al. ${ }^{[38]}$ who assessed changes in LOC during 14 days of auditory stimulation by familiar voice in comatose patients. They found that there was a statistically significant improvement in the LOC in experimental group than the control group. Gorji et al. ${ }^{[39]}$ conducted a double blind clinical trial to compare the effects of familiar and unfamiliar voices on recovering the consciousness in comatose patients. The subjects were randomly allocated into three groups. Group A was stimulated with a familiar voice, group B's auditory stimulation was done by the researcher and no intervention was done for group C (control group). The results revealed significant differences between the groups in the time to reach GCS $=15$ which happened sooner in group A and they recommended the implementation of auditory stimulation programs for comatose patients. Jones et al. ${ }^{[33]}$ examined physiological responses of unconscious patients to four different auditory stimuli (rock music, classical music, nature sounds, and family/friend voices). The findings suggested that taped voices of family and friends consistently resulted in greater increases in arousal than did other types of taped stimuli. Also Abbasi et al. ${ }^{[40]}$ investigated the effect of auditory and touching inputs in addition to regular family meeting on comatose patients. They found that consciousness level in the intervention group was significantly higher than the control group.

In the current study time of regaining consciousness was different in intervention and control groups. The intervention group reached to consciousness in shorter time than the control group. Some recent studies assessed the time to reach the level of consciousness after employing a variety of auditory stimuli. In a more recent study Gorji et al. ${ }^{[41]}$ examined the impact of a familiar voice to consciousness level in coma patients. The experimental group was treated with a familiar recorded sound while the control group received only natural voices of environment. Their findings showed that duration to reach GCS = 15 was significantly shorter in the experimental group than the control group. Moreover, Hossein Zadeh et al. ${ }^{[42]}$ examined the effect of organized voice auditory stimulation, which was performed by a nurse, on the length of coma. The results indicated that the intervention group has become conscious from the 5th day and control group from the 10th day.

There are evidences in the literature that unconscious patients have neurological and physiological responses with verbal communication. ${ }^{[11,17,33,34,43]}$ The findings of the present study found that no physiological adverse effects of communication on patient's clinical condition and positive effects noted on the level of consciousness. Nearly all PAE parameters (HR, $\mathrm{RR}, \mathrm{BP}, \mathrm{CVP}, \mathrm{SaO}_{2}$ and $\mathrm{BGL}$ ) reflected both improvement and stability as an effect of the intervention, in contrast to those patients of the control group. Stability of these physiological parameters within the normal values may be attributed to the balancing effects of SCMs on both sympathetic and parasympathetic nervous system. These findings are consistent with results of Davis and Gimenez ${ }^{[44]}$ that reported unconscious patients who were exposed to early and repeated auditory sensory stimulation demonstrated a positive recovery of brain function without compromising cerebral dynamic or cardiopulmonary functions. Similarly, Walker et al. ${ }^{[11]}$ demonstrated no negative effects associated with exposure to taped familial voices, with no significant changes being observed in in intracranial pressure (ICP), 
$\mathrm{BP}$, pulse, RR, mean arterial pressure, $\mathrm{SaO}_{2}$ level, or level of restlessness for any of the study participants. On the contrary, evidence reported in the reviewed literature also clearly shows a correlation between verbal communication and increases in $\mathrm{BP}, \mathrm{HR}, \mathrm{RR}, \mathrm{ICP}$, body movement and facial movement. ${ }^{[33,34]}$ Likewise, Hotz et al. ${ }^{[45]}$ found that sensory stimulation lead to a decrease in cardiac rhythm and blood pressure that lasted 2-3 hours after termination of the stimulus. Moreover, Puggina et al. ${ }^{[43]}$ found that the statistically significant alterations were in the variables oxygen saturation, and breathing frequency. They concluded that the familiar voice message was a stronger stimulus than the music. The present study revealed that the control group had a significantly higher incidence rate of PAE than patients in the intervention group. Also the results showed a larger variability and instability of physiological parameters for control group throughout the study period. These findings can be referred to the adverse effects of various alarms from cardiac monitors, infusion pumps and mechanical ventilators. These alarms are stressful to comatose patients and lead to stimulation of sympathetic nervous system and starting stress responses which in turn lead to changing in the values of vital signs. ${ }^{[46]}$ This hypothesis is supported by Lemke ${ }^{[47]}$ who stated that there are some triggers that immediately precede a sympathetic storming episode (a state of agitation, extreme posturing/dystonia, tachycardia, tachypnea, hypertension, diffuse diaphoresis, and hyperthermia within seconds), which may include suctioning, repositioning, uncontrolled environmental stimulation (alarms and equipment), or fever.

Interestingly, our results also suggest that implementation of SCMs was associated with reduced level of restlessness and pain as measured by MASS and BPS. This could be attributed to the soothing effect of caring touch that is involved in the SCMs. It is documented that touch triggers a cascade of healing chemical responses including a decrease in stress hormones and an increase in serotonin and dopamine levels. The shift in these bio-chemicals has been proven to decrease anxiety, depression, hyperactivity and inattention. Additionally, touch has been shown to increase the immune system's cytotoxic capacity, thereby helping our body maintain its defenses against pathogens. ${ }^{[8,48]}$ This may explain why patients in the intervention group displayed more comfort behaviours as measured by MASS and BPS than the control group. There is evidence in literature that care should be personalized through the use of effective communication strategies, such as by talking directly to the unconscious patient and using touch to enhance communication and convey emotional support. ${ }^{[12]}$ However, as with any aspect of care, this needs to be assessed individually as touch can also be interpreted as invasive or threatening. ${ }^{[8]}$

Published by Sciedu Press
Regarding the effect of family participation in SCMs during the present study, a special experience was felt during data collection when direct contact with the patient's family took place. Through family contact an insight into the patient's history as a human being was achieved. The wording of verbal communication messages was affectionate and meaningful to the patient. The improvement of patients' clinical conditions during the current study could be attributed to family participation in application of SCMs. This idea supported by, Laureys et al. ${ }^{[49]}$ and Boly et al. ${ }^{[50]}$ who indicated that auditory conversation with emotional content, such as the patient's own name by familiar voice, induced extensive brain activation than sounds without meaning. This implies that content is important when talking to unconscious patients. Other studies have confirmed no adverse effects on a patient's clinical condition due to hearing familiar voices, and positive effects noted on the LOC. ${ }^{[40,43]}$ Puggina et al. ${ }^{[43]}$ reported similar observations in a study comparing the use of two forms of auditory stimulation (a taped familial message and music). The taped message by a family member was shown to be more effective as a stimulus, as measured by changes in physiological parameters. Study findings of Abbasi et $a l .{ }^{[40]}$ revealed that family members involved in patients' communication had highly positive stimulating effects on all over brain functions. These studies suggest that unconscious patients retain a degree of perception, and encouraging a patients' family to communicate with them can provide an effective means of early stimulation. The opportunities for family interaction and communication with patients of the control group were often limited.

Regarding secondary outcomes after application of SCMs for intervention group, the data of the current study showed that there was a significant decrease in mean duration of $\mathrm{MV}$ as compared with patients of the control group. This could be attributed to higher mental functions that were reflected on patient's ability to protect airway and maintain spontaneous breathing. This hypothesis supported by Othman ${ }^{[51]}$ who reported that patient's LOC affects the duration of MV, as high LOC was accompanied with a decreased duration of MV. Findings of the current study revealed that there was a significant decrease in ICU length of stay after implementation of SCMs for intervention group than patients of the control group.

\section{Conclusion}

In conclusion, the study findings are interesting and could contribute to evidence supporting the introduction of SCMs in critical care nursing practice. The implementation of SCMs had effects on promotion of LOC, sedation level and reduction of pain and restlessness among unconscious 
patients. Communication with unconscious patients using SCMs was associated with a decreased incidence of PAE (hyperthermia, hypothermia, tachycardia, bradycardia, hypertension, hypotension, hypovolemia, hypervolemia, desaturation, bradypnea, ventilatory distress, hyperglycemia or hypoglycemia). Moreover, it was effective in decreasing duration of MV and ICU LOS.

\section{Recommendations}

On the basis of the most important findings of the study, the following recommendations are suggested:

- Critical care nurses should talk to unconscious patients and the SCMs should be incorporated into a nurse's daily routine in the care of unconscious patients.

- Structures, routines and time planning in the ICUs may need adjustment to raise possibility for the nurses to be prepared for application of SCMs.

- Verbal and non-verbal communication between patients and close family members may be a useful strategy to hasten recovery or provide inner peace for the unconscious patients.

- There is a need to place more emphasis on communication with unconscious patients in undergraduate and postgraduate critical care nursing programs. We hope that it will lead nurses to reflect on their practices in communication with unconscious patients so that they do not view communication as a second priority.

- Practical workshops on SCMs with unconscious patients are deemed necessary as they will have a positive impact on the ICU nurses caring for these patients.

- Study results confirm previous observations that communication implemented at an early stage of coma is beneficial to unconscious patients. This theme is a concept rarely studied in Egypt, and most definitely more research is necessary.

- The current study findings need to be further validated through studies with larger sample sizes.

- Future research related to SCMs could focus on performing long-term follow-up to compare cognitive and functional abilities outcomes in unconscious patients.

\section{ACKNOWLEDGEMENTS}

The authors express their gratitude and great thanks for the medical and nursing staff in all ICUs where the study was performed for their generous assistance and cooperation.

\section{CONFlicts OF INTEREST Disclosure}

The authors declare that there is no conflict of interest statement.

\section{REFERENCES}

[1] Jesus LM, Simões JF, Voegeli D. Verbal communication with unconscious patients. Acta Paul Enferm. 2013; 26(5): 506-13. http: //dx.doi.org/10.1590/S0103-21002013000500016

[2] Hemsley B, Balandin S, Worrall L. Nursing the patient with complex communication needs: time as a barrier and a facilitator to successful communication in hospital. J Adv Nurs. 2012; 68(1): 116-26. PMid:21831131 http://dx.doi.org/10.1111/j.136 5-2648.2011.05722.x

[3] Baker C, Melby V. An investigation into the attitudes and practices of intensive care nurses towards verbal communication with unconscious patients. J Clin Nurs. 1996; 5(3): 185-92. PMid:8705084 ht tp://dx.doi.org/10.1111/j.1365-2702.1996.tb00248.x

[4] Fleischer S, Berg A, Zimmermann M, et al. Nurse patient interaction and communication: A systematic literature review. J Public Health (Bangkok). 2009; 17(5): 339-53. http://dx.doi.org/10.1007 /s10389-008-0238-1

[5] Yava A, Tosun N, Ünver V, et al. Patient and nurse perceptions of stressors in the intensive care unit. Stress and Health. 2011; 27(2): e36-e47. http://dx.doi.org/10.1002/smi.1333

[6] Alasad J, Ahmad M. Communication with critically ill patients. Journal of Advanced Nursing. 2005; 50(4): 356-62. PMid:15842442 http://dx.doi.org/10.1111/j.1365-2648.2005.03400.x

[7] Magnus VS, Turkington L. Communication interaction in ICUPatient and staff experiences and perceptions. Intensive Crit. care Nurs. 2006; 22(3): 167-80. http://dx.doi.org/10.1016/j.i ccn.2005.09.009

[8] Geraghty M. Nursing the unconscious patient. Nursing Standard. 2005; 20(1): 54-64. PMid: 16178324

[9] Sisson R. Effects of auditory stimuli on comatose patients with head injury. Heart Lung. 1990; 19: 373-8.

[10] Simões J, Jesus L, Voegeli D, et al. The effects of acoustic stimulation on comatose patients. In: Silva E (Eds) Comas and Syncope: Causes, Prevention and Treatment. New York: Nova Science; 2012. 1-31.

[11] Walker J, Eakes G, Siebelink E. The effects of familial voice interventions on comatose head-injured patients. Journal of Trauma Nursing. 1998; 5 (2): 41-45. http://dx.doi.org/10.1097/00043860-1 99804000-00006

[12] Lawrence M. The unconscious experience. American Journal of Critical Care. 1995; 4(3): 227-32. PMid:7787917

[13] LaPuma J, Schiedermayer D, Galias A, et al. Talking to comatose patients. Neurotrauma Medical Report. 1990; 4: 1-3.

[14] Goudarzi F, Basampoor S, Zakeri-Moghadam M, et al. Changes in level of consciousness during auditory stimulation by familiar voice in comatose patients. Iran Journal of Nursing. 2010; 23(63): 43-50.

[15] Elliot R, Wright L. Verbal communication: what do critical care nurses say to their unconscious or sedated patients. Journal of Advanced Nursing. 1999; 29(6): 1412-20. http://dx.doi.org/10. 1046/j.1365-2648.1999.01028.x

[16] Lazarus RS, Folkman S. Stress, appraisal and coping. New York: Springer Publishing Company; 1984. 142.

[17] Holeckova I, Fischer C, Giard M, et al. Brain responses to a subject's own name uttered by a familiar voice. Brain Research. 2006; 1082(1): 142-52. http://dx.doi.org/10.1016/j.brainres.2006.01.089

[18] Bickmore TW, Fernando R, Ring L, et al. Empathic Touch by Relational Agents. IEEE Transactions on Affective Computing. 2010; 1(1): 60-71. http://dx.doi.org/10.1109/T-AFFC. 2010.4 
[19] Ibrahim YM. Practices of critical care nurses towards verbal communication with unconscious patients. Bulletin of High Institute of Public Health. 2001; 31(4): 845-58.

[20] Thomas D. A study to assess the effectiveness of planned teaching program for nurses working in ICU of St. John's Medical College Hospital, Bangalore on communication to unconscious patients. Master thesis of medical surgical nursing. College of nursing, John's national academy of health science, Bangalore 2006.

[21] Puggina A, Silva M, Schnakers C, et al. Nursing care of patients with disorded of consciousness. Journal of neurodcience nursing. 2012; 44(3): 260-70. PMid:22955240 http://dx.doi.org/10.1097/J NN. Ob013e3182666407

[22] Laureys S, Schiff ND. Coma and consciousness: paradigms (re)framed by neuroimaging. Neuroimage. 2012; 61(2): 478-91. PMid:22227888 http://dx.doi.org/10.1016/j.neuroimage. 2011.12 .041

[23] Wijdicks EF. Clinical scales for comatose patients: The Glasgow Coma Scale in historical context and the new FOUR Score. Reviews in Neurological Disease. 2006; 3(3): 109-17. PMid:17047576

[24] Payen J, Bru O, Bosson J, et al. Assessing pain in critically ill sedated patients by using a behavioural pain scale. Crit Care Med. 2001; 29(12): 2258-63. http://dx.doi.org/10.1097/0000324 6-200112000-00004

[25] Devlin JW, Boleski G, Mlynarek M, et al. Motor Activity Assessment Scale: a valid and reliable sedation scale for use with mechanically ventilated patients in an adult surgical intensive care unit. Crit Care Med. 1999; 27: 1271-75. http://dx.doi.org/10.1097/00003 246-199907000-00008

[26] Iyer VN, Mandrekar JN, Danielson RD, et al. Validity of the FOUR Score Coma Scale in the Medical Intensive Care Unit. Mayo Clin Proc. 2009; 84(8): 694-701. http://dx.doi.org/10.4065/84. 8.694

[27] Puggina AC, Silva M J, Araújo MM. Messages from relatives of patients in coma: Hope as common element. Acta Paul Enferm. 2008; 21(2): 249-55. http://dx.doi.org/10.1590/S0103-2100200 8000200003

[28] Happ MB, Garrett K, Thomas DD, et al. Nurse-patient communication interaction in the intensive care unit. American Journal of Critical Care. 2011; 20(2): e28-40. PMid:21362711 http://dx.d oi .org/10.4037/ajcc2011433

[29] Schweickert WD, Kress JP. Strategies to Optimize Analgesia and Sedation. Critical Care. 2008; 12(3): S5. http://dx.doi.org/10. $1186 / \operatorname{cc} 6151$

[30] Dithole KS. Nurses' communication with mechanically ventilated patients in the intensive care units. Doctor thesis. Health Study. University of South Africa; 2014.

[31] Gergis MA. Caring behavior and ability of nurses in the intensive care units. Master thesis, Faculty of Nursing, Alexandria University, Egypt, 2007.

[32] Bach-Y-Rita P. Theoretical basis for brain plasticity after a TBI. Brain Injury. 2003; 17(8): 643-51. http://dx.doi.org/10.1080/026 9905031000107133

[33] Jones R, Hux K, Morton-Anderson KA, et al. Auditory stimulation effect on a comatose survivor of traumatic brain injury. Arch Phys Med Rehabil. 1994; 75(2): 164-71. PMid:8311672

[34] Perrin F, Schnakers C, Schabus M, et al. Brain response to one's own name in vegetative state, minimally conscious state, and lockedin syndrome. Arch Neurol. 2006; 63(4): 562-9. PMid:16606770 http://dx.doi.org/10.1001/archneur.63.4.562

[35] Tolle P, Reimer M. Do we need stimulation programs as a part of nursing care for patients in "persistent vegetative state?" A conceptual analysis. AXON. 2003; 25(2): 20-6. PMid:14733174
[36] Urbenjaphol P, Jitpanya C, Khaoropthum S. Effects of the sensory stimulation program on recovery in unconscious patients with traumatic brain injury. Journal of neuroscience nursing. 2009; 41(3): E10E16. http://dx.doi.org/10.1097/JNN.0b013e3181a23e94

[37] Karma D, Rawat AK. Effect of stimulation in coma. Indian Pediatr. 2006; 43(10): 856-60. PMid:17079828

[38] Goudarzi F, Basampoor S, Zakeri-Moghadam M, et al. Changes in level of consciousness during auditory stimulation by familiar voice in comatose patients. Iranian Journal of Nursing. 2010; 23: 43-50.

[39] Gorji MA, Mojarad FA, Jafari H, et al. Comparing the effects of familiar and unfamiliar voices as auditory sensory stimulation in level of consciousness among traumatic comatose patients in intensive care unit. J Mazand Univ Med Sci. 2013; 23(97): 208-14.

[40] Abbasi M, Mohammadi E, Sheaykh Rezayi A. Effect of a regular family visiting program as an affective, auditory, and tactile stimulation on the consciousness level of comatose patients with a head injury. Jpn J Nurs Sci. 2009; 6: 21-6. PMid:19566636 http://dx.doi.org/10.1111/j.1742-7924.2009.00117.x

[41] Gorji MA, Araghiyansc F, Jafari H, et al. Effect of auditory stimulation on traumatic coma duration in intensive care unit of Medical Sciences University of Mazandarn, Iran. Saudi Journal of Anesthesia. 2014; 8(1): 69-72. http://dx.doi.org/10.4103/1658-354X 125940

[42] HosseinZadeh E, Mahmoodi SR, Vakili MA, et al. The effect of voice auditory stimulation on the consciousness of the coma patients suffering from head injury. J Res Dev Nurs Midwifery. 2013; 10(1) $1-9$.

[43] Puggina A, Paes da Silva MJ, Ferreira Santos JL. Use of music and voice stimulus on patients with disorders of consciousness. J Neurosci Nurs. 2011; 43(1): E8-E16. http://dx.doi.org/10.1097 /JNN. Ob013e3182029778

[44] Davis AE, Gimenez A. Cognitive-behavioral recovery in comatose patients following auditory sensory stimulation. Journal of Neuroscience Nursing. 2003; 35(4): 202-214. PMid:12942654 http: //dx.doi.org/10.1097/01376517-200308000-00006

[45] Hotz GA, Castelblanco A, Lara IM, et al. Snoezelen: A controlled multi-sensory stimulation therapy for children recovering from severe brain injury. Brain Injury. 2006; 20(8): 879-88. PMid:17046800 http://dx.doi.org/10.1080/02699050600832635

[46] Zhang Y. Real-time analysis of physiological data and development of alarm algorithms for patient monitoring in the intensive care unit Master thesis. Faculty of Engineering. Massachusetts Institute of Technology; 2003.

[47] Lemke DM. Sympathetic storming after severe traumatic brain injury. Critical Care Nurse. 2007; 27: 30-37. PMid:17244857

[48] Henricson M, Ersson A, Määttä S, et al. The outcome of tactile touch on stress parameters in intensive care: a randomized controlled trial. Clin Pract. 2008; 14(4): 244-54. http://dx.doi.org/10.1016 /j.ctcp.2008.03.003

[49] Laureys S, Perrin F, Faymonville ME, et al. Cerebral processing in the minimally conscious state. Neurology. 2004b; 63(5): 91618. PMid:15365150 http://dx.doi.org/10.1212/01.WNL . 00 $00137421.30792 .9 \mathrm{~B}$

[50] Boly M, Faymonville ME, Peigneux P, et al. Cerebral processing of auditory and noxious stimuli in severely brain injured patients: differences between VS and MCS. Neuropsychol Rehabil. 2005; 15(3-4): 283-89. PMid:16350972 http://dx.doi.org/10.1080 /09602010443000371

[51] Othman SY. Effect of implementing weaning guidelines on clinical outcomes among mechanically ventilated patients. Doctor thesis. Faculty of Nursing, University of Alexandria. Egypt; 2008. 